\section{Stroke and infective endocarditis}

Anderson et al. studied 68 patients with stroke and infective endocarditis (IE). They classified strokes by subtype, severity, and vascular distribution. Patients with mitral value IE were at higher risk for stroke than patients with aortic value IE. Overall mortality was 52\% at 12 months.

see page 1341

The accompanying editorial by Piechowski-Jóźwiak and Bogousslavsky reviews the complications of endocarditis: heart failure, peripheral embolism, neurologic disorders, sepsis, acute renal failure, metastatic abscesses, and mycotic aneurysms. The most common neurologic disorder is stroke, followed by encephalopathy, retinal emboli, mycotic aneurysm, abscess, meningitis, and seizures. Noting that clearer identification of high-risk IE patients will lead to better treatment strategies in patients with infectious endocarditis-related stroke, they point out that mortality remains high despite antibiotic treatment. Anticoagulants are not of established benefit (or hazard).

see page 1324

\section{Effect of myasthenia gravis on risks of giving birth}

Midelfart Hoff et al. studied all 127 births by women with MG in Norway between 1967 and 2000 and compared them to all other births in that period. A higher rate of complications and interventions during birth was found: preterm rupture of amniotic membranes was threefold higher; cesarean sections were twofold higher; and five children had severe anomalies, three of them fatal.

see page 1362

\section{Atypical cerebral laterality in developmental stuttering}

Foundas et al. studied 16 adults with developmental stuttering and 16 matched controls. Controls had the "typical" rightward frontal lobe and leftward occipitalparietal lobe asymmetry. In contrast, developmental stuttering was associated with atypical lobar asymmetry patterns, a potential marker of atypical cerebral laterality. Deficits in language processing were associated with some anatomic measures in the adults who stutter.

see page 1378

\section{Outcome of children treated for vein of Galen malformations}

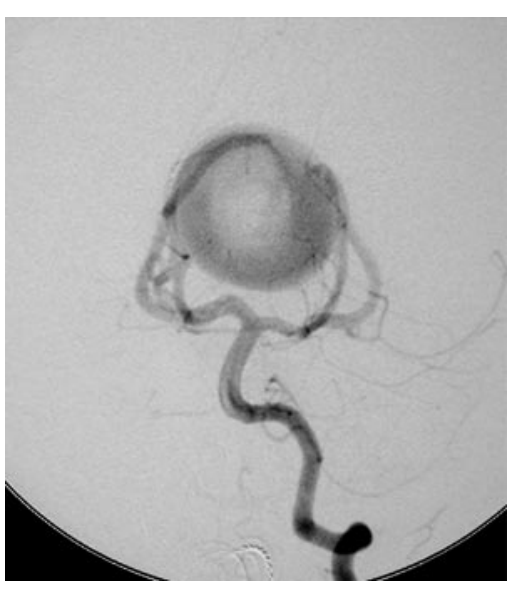

A-P view of mural-type vein of Galen malformations.
In a study of 27 children treated for vein of Galen malformations, typically thought to have a poor prognosis, Fullerton et al. found that 14 had a favorable neurodevelopmental outcome. Features associated with worse outcome were perinatal presentation, congestive heart failure, and choroidal angioarchitecture.

see page 1386

\section{Human herpesvirus-6 in mesial temporal lobe epilepsy}

Mesial temporal lobe epilepsy (MTLE) accounts for a substantial fraction of all epilepsies yet its etiology remains incompletely defined. Donati et al. have demonstrated elevated levels of the human herpesvirus HHV-6B DNA in hippocampal and temporal lobe samples obtained from surgical resections from four of eight patients with MTLE vs no virus in seven patients with neocortical epilepsy. HHV-6 expression colocalized to GFAP-positive astrocytes.

see page 1405

\section{Endovascular embolectomy: A new therapy for stroke}

$\mathrm{Yu}$ et al. report a patient with acute basilar artery occlusion successfully treated with endovascular embolectomy 7 hours after onset, suggesting that mechanical removal of a clot deserves evaluation as a therapy for stroke.

see page 1421 
Restless legs syndrome and hypocretin-1

Stiasny-Kolster et al. found normal early evening CSF hypocretin-1 levels in patients with early- and late-onset RLS. This observation argues against a significant involvement of this neuropeptide in RLS.

see page 1426

Silent mutation in McArdle's disease: A villain hidden behind a mask

Fernandez-Cadenas et al. report a silent mutation in the gene encoding myophosphorylase that was associated with aberrant splicing of its RNA with consequent loss of the functional enzyme in muscle.

see page 1432

In the accompanying editorial, Mankodi and Ashizawa discuss pathogenic silent mutations in neuromuscular diseases. As silent mutations do not predict change in the genetic code for protein synthesis, they are not expected to cause disease. However, there is recent evidence that silent mutations, when situated within exonic splicing-enhancer sequences, have the same detrimental effect on the activity of proteins as that seen with nonsense mutations. They do so by interfering with the splicing in the neighboring regions in their RNA and thereby changing the protein code of RNA level. As Fernandez-Cadenas et al. show, RNA analysis must be added to genetic screening procedures to expose the villainous side of splicing silent mutations. Moreover, in some diseases-e.g., spinal muscular atrophy-aberrant splicing associated with silent mutations may be correctable and provide a novel approach to treatment.

see page 1330

\section{MPZ mutations and very late onset CMT2 syndrome}

Auer-Grumbach et al. found that late-onset and rapidly progressive Charcot-Marie-Tooth (CMT) 2 disease caused by MPZ gene mutations can mimic chronic polyradiculoneuritis. Molecular genetic testing in lateonset neuropathies may be important.

see page 1435

\section{Hereditary neuropathy pressure palsies mimicking hypoglossal nerve injuries}

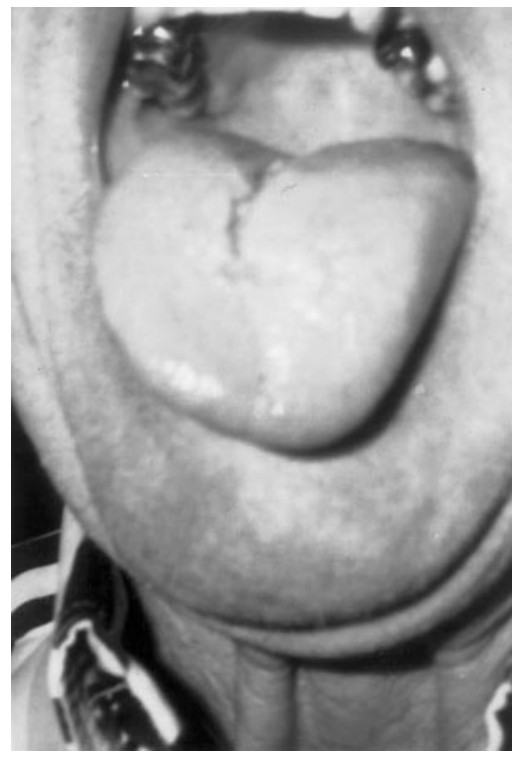

Corwin and Girardet describe a patient with HNPP who developed bilateral traction hypoglossal neuropathy during carotid endarterectomy. see page 1457

\section{Mycophenolate mofetil for myasthenia gravis}

Meriggioli et al. analyzed the use of mycophenolate mofetil (MyM) in 85 patients with myasthenia gravis. Sixty-two patients $(73 \%)$ improved by clinical criteria. There were side effects in $27 \%$.

see page 1438

\section{Levodopa addiction in non- parkinsonian patients}

Steiner and Wirguin report five non-parkinsonian patients who developed signs and symptoms of addiction to levodopa. Thus, levodopa may possess reinforcing properties beyond its motor effects.

see page 1451 


\title{
Neurology
}

\author{
November 25 Highlights \\ Neurology 2003;61;1322 \\ DOI 10.1212/WNL.61.10.1322
}

This information is current as of November 24, 2003

\section{Updated Information \&}

Services

Permissions \& Licensing

Reprints including high resolution figures, can be found at: http://n.neurology.org/content/61/10/1322.full

Information about reproducing this article in parts (figures,tables) or in its entirety can be found online at:

http://www.neurology.org/about/about_the_journal\#permissions

Information about ordering reprints can be found online:

http://n.neurology.org/subscribers/advertise

Neurology ${ }^{\circledR}$ is the official journal of the American Academy of Neurology. Published continuously since 1951, it is now a weekly with 48 issues per year. Copyright . All rights reserved. Print ISSN: 0028-3878. Online ISSN: 1526-632X.

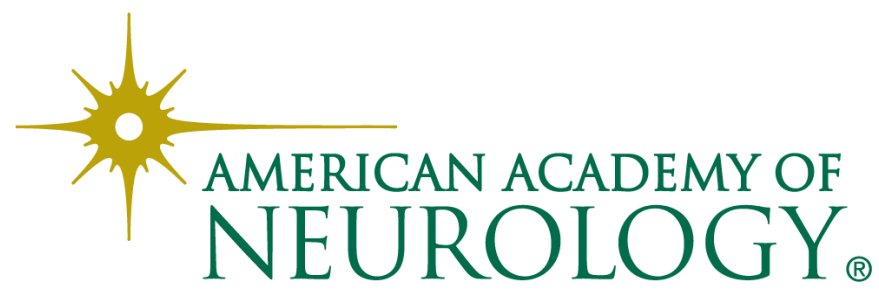

